\title{
Wettability and Surface Morphology Investigation of RGP Eye Contact Lens Irradiated by 193 nm Excimer Laser
}

\author{
Tayebeh Ariyafar1, Ali Pourakbar Saffar2*, Peyman Tajalli1, Habib Tajalli3 \\ ${ }^{1}$ Physics Department, Islamic Azad University, East Azarbaijan Science and Research Branch, Tabriz, Iran \\ ${ }^{2}$ Laser Laboratory, Research Center of Informatic Industries, Tehran, Iran \\ ${ }^{3}$ Excellence in Photonics, University of Tabriz, Tabriz, Iran \\ Email: ${ }^{*}$ a pourakbar@iauctb.ac.ir, ${ }^{*}$ a.pourakbar@yahoo.com
}

Received 27 March 2015; accepted 11 April 2015; published 15 April 2015

Copyright (C) 2015 by authors and OALib.

This work is licensed under the Creative Commons Attribution International License (CC BY). http://creativecommons.org/licenses/by/4.0/

CC) (i) Open Access

\begin{abstract}
In this work, Rigid gas permeable (RGP) contact lenses based on Fluoro Silicone Acrylate, were irradiated by using $193 \mathrm{~nm}$ ArFexcimer laser, at $1 \mathrm{~Hz}$ pulse repetition rate with $75 \mathrm{~mJ} /$ pulse energy to improve surface wettability. We investigated the morphology of the ablated area by imaging the surface modification with Atomic force microscopy (AFM) with roughness analysis and Scanning electron microscopy (SEM). Characterization techniques were performed too via contact angle measurement in order to determine the surface wettability and Fourier transform infra-red spectroscopy (FTIR). The morphological appearance of samples reveals the effect of a photochemical and photothermal ablation mechanism. The laser irradiation without changing the chemical bonds has modified the lens surface properties and increased the surface hydrophilicity. Morphological surface changes with laser exposure and the water contact angle decreases as the surface of the fluorosilicone acrylate material is modified.
\end{abstract}

\section{Keywords}

Contact Lens, Excimer Laser, Hydrophilicity, Microscopy, Spectroscopy

Subject Areas: Applied Physics, Biophysics, Ophthalmology, Surface and Intersurface of Materials

\section{Introduction}

Rigid gas permeable (RGP) contact lenses are manufactured by mixing silicone methacrylate (SMA) or fluorosilicone acrylate (FSA) with polymethyl methacrylate (PMMA), which is known to be a hard contact lens material. These polymers, which are mixed for improved oxygen transmissivity, have hydrophobicity. The tear wetting of

*Corresponding author.

How to cite this paper: Ariyafar, T., Saffar, A.P., Tajalli, P. and Tajalli, H. (2015) Wettability and Surface Morphology Investigation of RGP Eye Contact Lens Irradiated by 193 nm Excimer Laser. Open Access Library Journal, 2: e1463.

http://dx.doi.org/10.4236/oalib.1101463 
the lens surface is low, and the lens is uncomfortable to wear. The surfaces of RGP contact lenses based on fluorosilicone acrylate were treated by using plasma in the air. Compositions and morphologies, which influence changes in wettability, were observed. Boston $\mathrm{XO}$ and $\mathrm{XO}_{2}$ contact lenses were modified using plasma technology [1] [2]. Atomic force microscopy (AFM) provides detailed information on the surface characteristics of contact lenses [3]-[5].

Development of laser-assisted modification of polymer surfaces is rapidly growing and the method has gained considerable interest among scientists in the past decade. A substantial several experiments and studies have been carried out by using a laser to alter the surface property of materials. Interaction of UV laser pulses with polymers and biological tissues led to a discovery in 1982 of ablative photo decomposition that resulted in the break-up of the structure of organic solid by the photons and the expulsion of the fragments at supersonic velocities [6]. UV laser ablation of polymers can be efficiently done by various excimer lasers such as XeF (350 nm), $\mathrm{XeCl}(308 \mathrm{~nm}), \mathrm{KrF}(248 \mathrm{~nm})$ and $\operatorname{ArF}(193 \mathrm{~nm})$ as well as laser with shortest UV wavelength, i.e. molecular fluorine laser $(157 \mathrm{~nm})$ [7] [8]. Many studies have also examined the stability of different polymers under UV and IR light, for example [9]-[15]. The polymers investigated included polymethylmethacrylate (PMMA), PVC, polypropylene (PP) and polycarbonate (PC). Among many polymeric materials, PMMA has been the most intensively examined target material to elucidate ablation mechanisms [15].

Experimental corneal models in plastic (in PMMA, and more recently in Filofocon A, a contact lens material) have been proposed recently to overcome some of the limitations of the theoretical approaches aiming at improving the predictability of corneal reshaping by laser ablation [16]. The ArFexcimer laser was used to ablate the cornea in human eye bank eyes under clinical conditions. Different corneal structural elements have different ablation threshold energy densities [17]. Alternatives to excimer laser sources, such as UV, or mid infrared solid state lasers are also investigated for corneal tissue and tissue simulators ablation. The aim of this study is to investigate the use of UV (266 nm) laser pulses to ablate the intraocular lens materials, and thus to provide an alternative to conventional surface shaping techniques for IOLs fabrication. Ablation experiments were conducted using various polymer substrates of hydrophobic acrylic IOLs and PMMA IOLs [18]. Smoother ablations of PMMA plates and porcine corneas were obtained by the laser [19].

The surface properties of collagen and collagen/poly (vinyl pyrrolidone) (PVP) films after KrFexcimer laser irradiation (248 $\mathrm{nm}$ ) were investigated [20]. The method using ArFexcimer laser was also successful even in polycarbonate film of $250 \mu \mathrm{m}$ thicknesses and cellulose acetate membranes, which its morphological changes with the enhanced wetting [21] [23].

\section{Experimental}

\subsection{Materials and Methods}

We have utilized RGP contact lenses (Boston EO) of $9.6 \mathrm{~mm}$ diameter, manufactured by (Interojo Inc.) as a target. The excimer laser (Lambda Physik ${ }^{\mathrm{TM}}$, LPX 210) of $193 \mathrm{~nm}, 350 \mathrm{~mJ} /$ pulse, and $15 \mathrm{~ns}$ pulse duration was used at 1 - $10 \mathrm{~Hz}$ pulse repetition rate, as the coherent UV source.

\subsection{Surface Characterization}

The lens morphology has been studied using an atomic force microscope (Nanowizard, JPK, Germany) and a scanning electron microscope (Seron Technology AIS2100) accompanied with a sputter coater (EMITECH, SC7620). Scanning electron microscope with secondary electron detector (SE) is used to observe the surface of detector precisely. The polymeric surface usually has no electrical conductance; hence a 10 - $15 \mathrm{~nm}$ gold layer must be provided by sputter coating, to remove electrostatic charge from the surface due to electron beam radiation.

In Atomic Force Microscopy the topography is mapped out by measuring the mechanical force exerted on the tip due to the tip-surface interaction. AFM has the capability to determine the surface structure of conducting and insulating materials. Both techniques can be used in a vacuum, in air and in liquids. Digital monitoring of surface topography makes it possible to estimate the surface roughness by means of the two parameters: root mean square heights within a given area, i.e. $\mathrm{R}_{\mathrm{q}}$ (denoted also as RMS) and $\mathrm{R}_{\mathrm{a}}$ (mean roughness) [22] [24]. For imaging lens surface on the nanometer scale, AFM was employed in aqueous media. In the swollen state, roughness values of lens surfaces lie between 4 and $140 \mathrm{~nm}$ [5]. 
Profile measurements such as height profile represent a valuable utility of AFM. Section analysis enabled the performance of detailed measurements of all selected structures, both in horizontal and vertical planes. Measurements of difference in relative microstructures, depth of pores, and depth of the gap between the border rows were achieved. This option facilitates easy three-dimensional measurements of the observed structures, something not available in conventional scanning microscopy.

Surface hydrophobicity and wettability of lenses were evaluated from contact angle measurements by (Kruss G10) goniometer equipped with image analysis software. The sessile drop method is basically an optical contact angle method, which is the most frequented, used method to estimate wetting properties of a solid surface. A droplet of distilled water was deposited on the surface with a precision syringe. The method is based on image processing and curve fitting to contact angle measurement from theoretical meridian drop profile, measuring contact angle between the baseline of drop and the tangent at drop boundary. Video acquisition of a magnified image of drop profiles is conveyed to a computer via a CCD camera, which enables to quantify changes in droplet shape recorded as digital images over time. The contact angles were measured on both sides of the drop and averaged. The ATR/FTIR spectra of the samples are recorded in the range of $600-4000 \mathrm{~cm}^{-1}$ using a Fourier transform infrared spectrometer (Bruker-Equinox 55) to investigate the alteration of chemical bonds on the lens surface after laser irradiation.

\section{Results and Discussion}

RGP lenses were chosen for the laser treatment. They were exposed to ArFexcimer laser at various UV pulses with of $75 \mathrm{~mJ} /$ pulse energy, at $1 \mathrm{~Hz}$ pulse repetition rate (Figure 1).

\subsection{SEM and AFM}

In Figure 2 and Figure 3 we present the SEM and AFM micrographs of the reference and laser irradiated lenses at various laser pulses. The UV laser induced effects on the surface in terms of laser exposure condition.

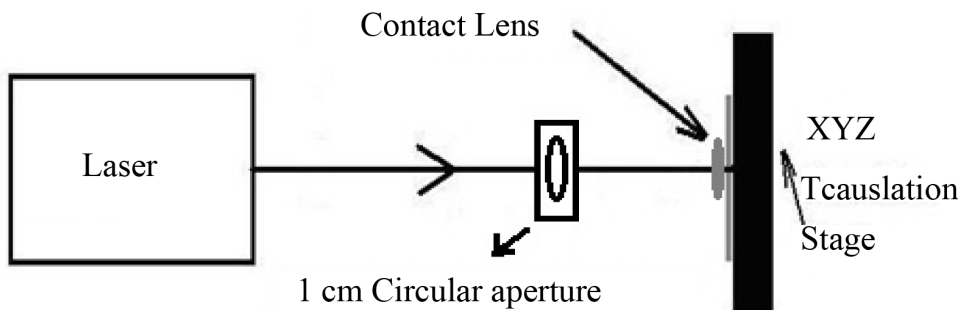

Figure 1. Schematic set up for laser irradiation on RGP lens.

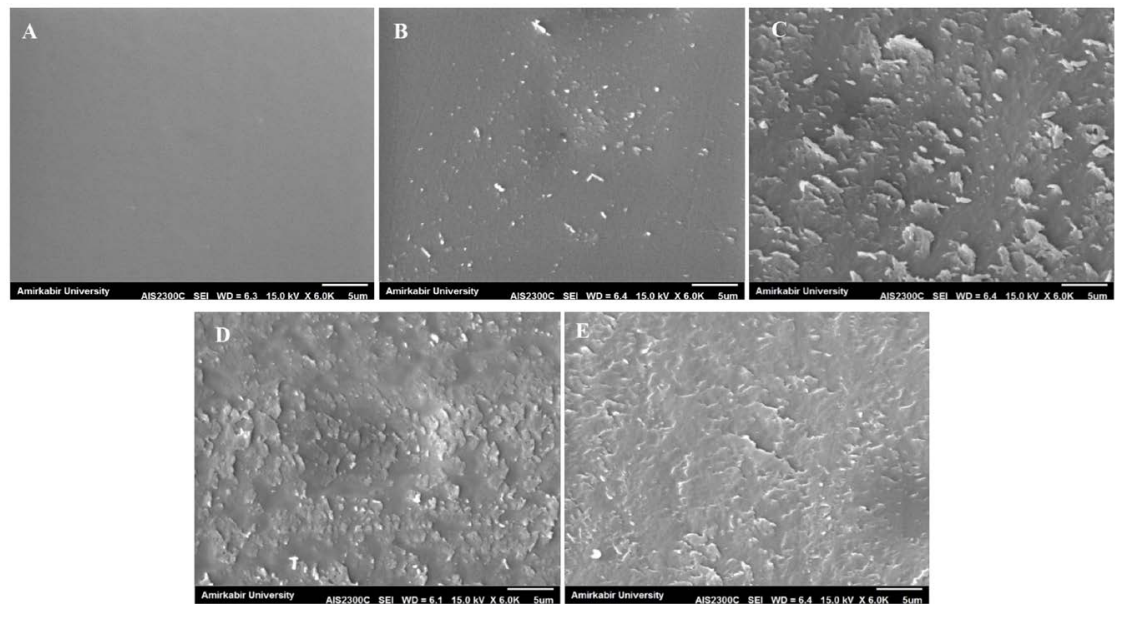

Figure 2. SEM micrographs of lenses, the untreated sample (A), 2 pulses, $0.19 \mathrm{~J} / \mathrm{cm}^{2}$ (B), 5 pulses, $0.475 \mathrm{~J} / \mathrm{cm}^{2}$ (C), 10 Pulses, $0.95 \mathrm{~J} / \mathrm{cm}^{2}$ (D), 20 Pulses, $1.9 \mathrm{~J} / \mathrm{cm}^{2}$ (E). 


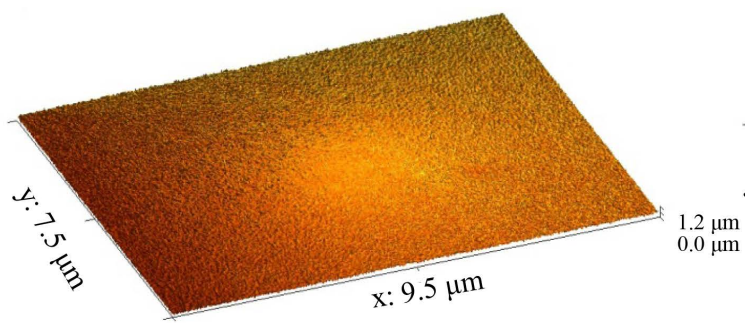

(A)

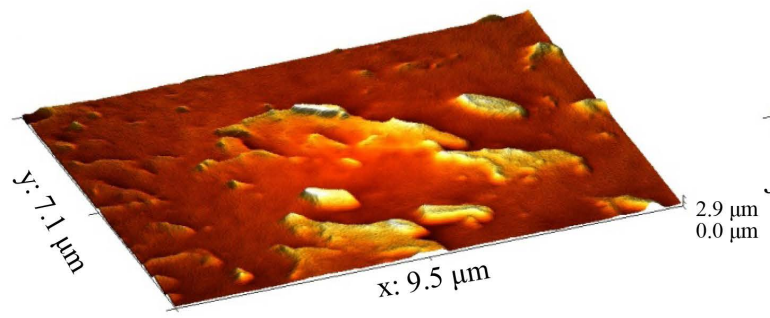

(C)

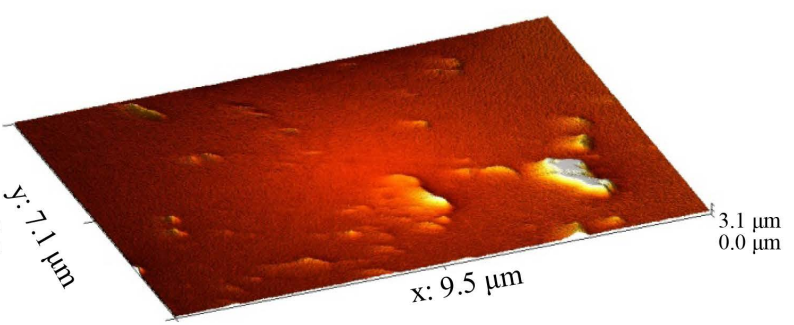

(B)

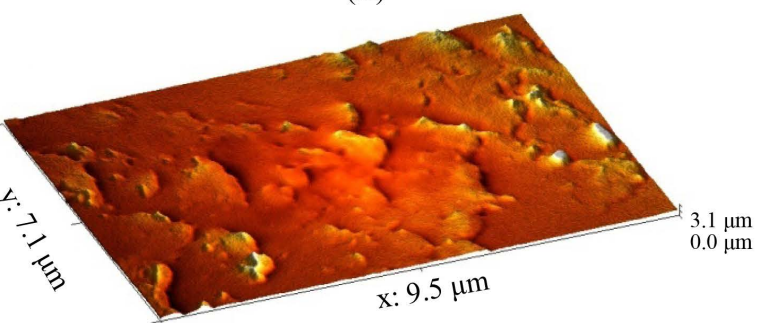

(D)

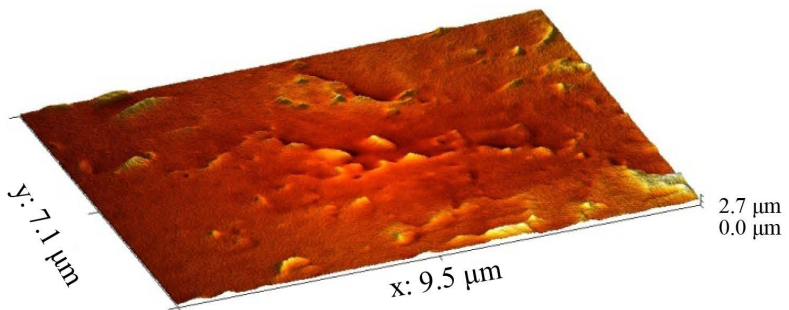

(E)

Figure 3. Three dimensional AFM topography images of lenses, the untreated sample (A), 2 pulses, $0.19 \mathrm{~J} / \mathrm{cm}^{2}$ (B), 5 pulses, $0.475 \mathrm{~J} / \mathrm{cm}^{2}$ (C), 10 Pulses, $0.95 \mathrm{~J} / \mathrm{cm}^{2}$ (D), 20 Pulses, $1.9 \mathrm{~J} / \mathrm{cm}^{2}$ (E).

Figure 2(A) and Figure 3(B) are presented the surface images of the Control lens before irradiation. Figures 2(B)-(E) and Figures 3(B)-(E) are presented the surface images of the RGP contact lenses after irradiation with excimer laser at laser fluences (in sequence) $0.19 \mathrm{~J} / \mathrm{cm}^{2}$ and 2 pulses, $0.475 \mathrm{~J} / \mathrm{cm}^{2}$ and 5 pulses, $0.95 \mathrm{~J} / \mathrm{cm}^{2}$ and 10 pulses, $1.9 \mathrm{~J} / \mathrm{cm}^{2}$ and 20 pulses.

It is obviously seen that the microstructures were revealed after irradiation and their population was increased in surface with the number of pulses. The roughness of lens surface due to laser treatment was measured in an effort to evaluate the distribution of roughness values. Roughness measurement, we used the RMS values with a reference surface of $9.5 \times 7.5 \mu \mathrm{m}^{2}$ and results are shown in Table 1 .

Based on the roughness results, we were able to distinguish after gradually increase roughness at 2 and 5 pulses at least surface roughness decreased up to 20 pulses. Two dimensional AFM topography images and corresponding height profiles along the indicated lines for RGP contact lens are shown in Figure 4. This height profile shows the topography variation over an RGP lens surface in reference and laser treated lenses according to variation of roughness values.

\subsection{Contact Angle Measurement}

A contact angle was measured as a function of UV laser pulses at $75 \mathrm{~mJ} /$ pulse and it is plotted, as shown in Figure 5. The smaller contact angle is corresponding to the greater UV doses. At higher doses, probably changes in surface morphology led to higher hydrophilicity of the lens surface.

After an initial decrease of wettability up to 5 pulses, surface hydrophilicity is increased with the increasing of pulse numbers. Here, threshold of contact angle reduction is in $0.475 \mathrm{~J} / \mathrm{cm}^{2}$. Investigation on wettability of the lens surface indicates that increase in hydrophilicity of the lens corresponding to the smaller contact angles takes place at higher doses. Furthermore, the alteration in contact angle becomes remarkable in the case of microstructuring at higher doses. 
Table 1. Roughness analysis of RGP contact lens from AFM images.

\begin{tabular}{cccc}
\hline Number of pulses & Laser fluencies $\left(\mathrm{J} / \mathrm{cm}^{2}\right)$ & $\mathrm{R}_{\mathrm{a}}(\mathrm{nm})$ & $\mathrm{R}_{\mathrm{q}}(\mathrm{nm})$ \\
\hline 0 (Reference) & 0 & 106 & 132 \\
2 & 0.19 & 171 & 294 \\
5 & 0.475 & 301 & 436 \\
10 & 0.95 & 260 & 350 \\
20 & 1.9 & 192 & 271 \\
\hline
\end{tabular}
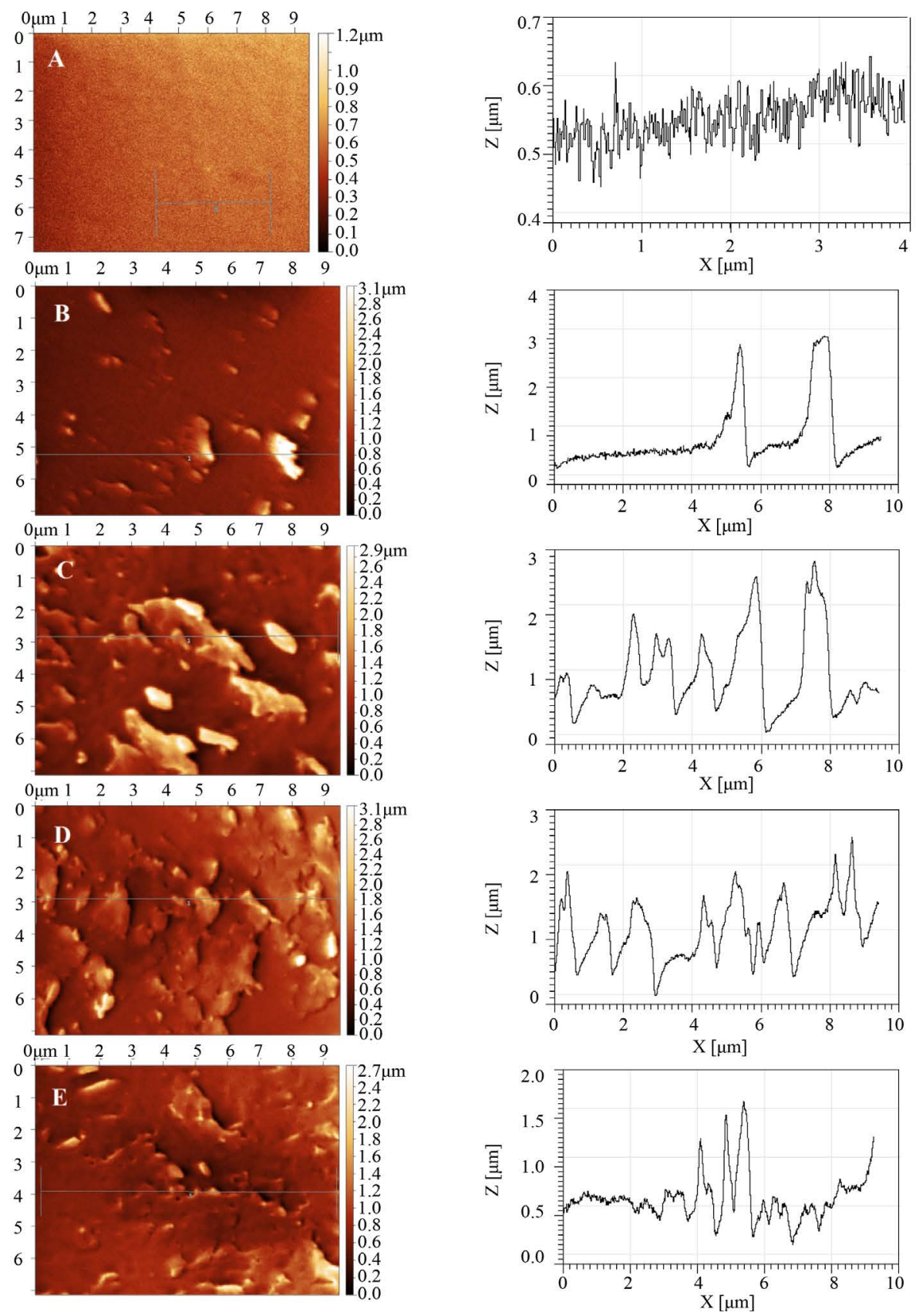

Figure 4. Two dimensional AFM topography images and corresponding height profiles along the indicated lines, the untreated sample (A), 2 pulses (B), 5 pulses (C), 10 Pulses, (D), 20 Pulses (E). 


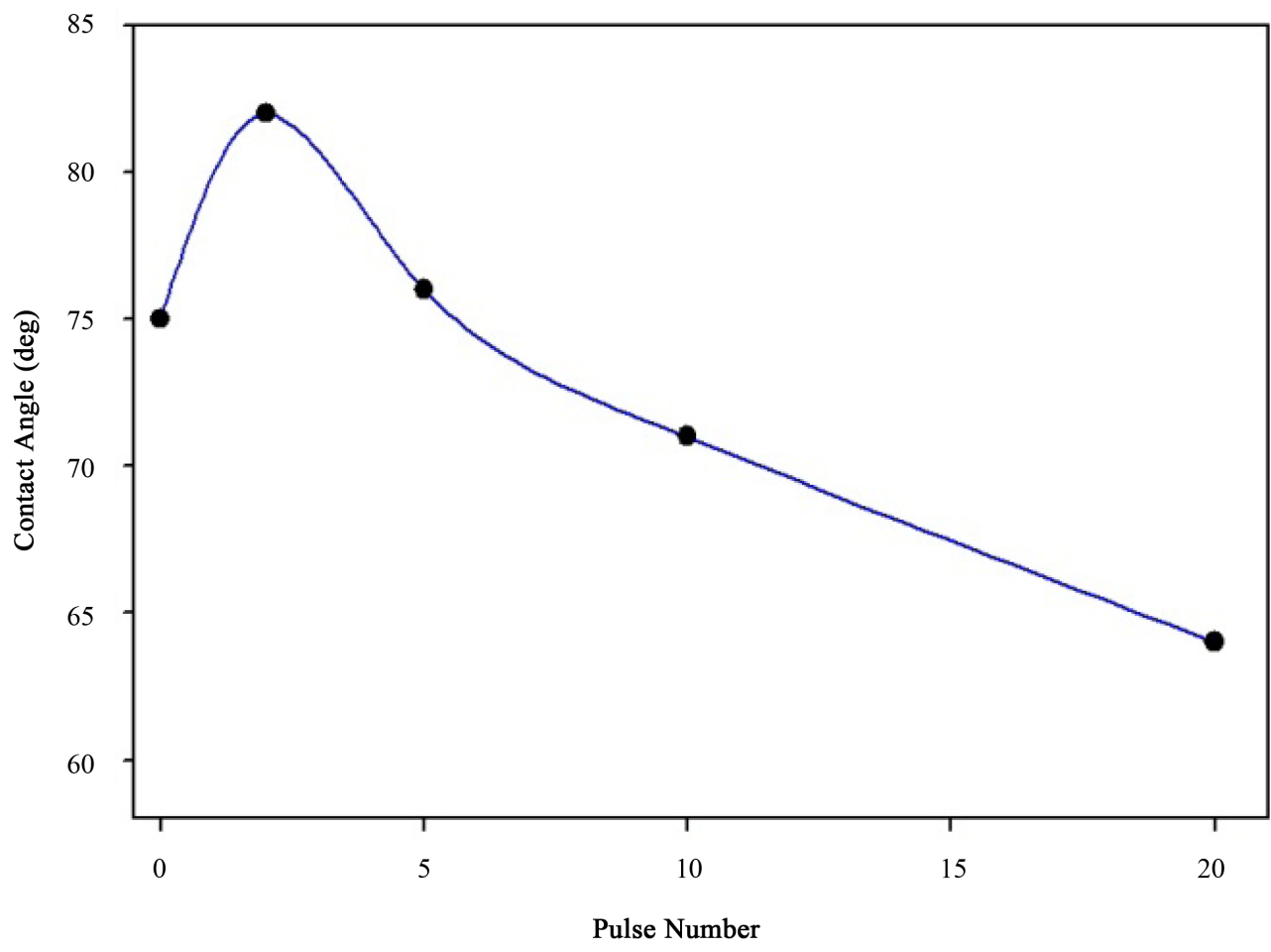

Figure 5. Contact angle measurement as a function of laser pulses.

\subsection{ATR/FTIR Spectroscopy}

ATR/FTIR has often been used as a useful tool in determining specific functional groups or chemical bonds that exist in a material. The presence of a peak at a specific wave number would indicate the presence of a specific chemical bond. In Figure 6, no significant alteration was observed compared with the reference and laser irradiated lenses, but the strength of the chemical bonds has been reduced. Three major peaks were chosen from the spectrum in order to determine the bonding changes due to the variation in exposure.

The peaks chosen are identified as C-O bonding of the acetyl group $\left(1231 \mathrm{~cm}^{-1}\right), \mathrm{C}=\mathrm{O}$ bonding of carbonyl group $\left(1727 \mathrm{~cm}^{-1}\right)$ and absorbance of the- $\mathrm{CH}_{2}$-group (2944 and $\left.2885 \mathrm{~cm}^{-1}\right)$, since these bonds show the most intense transmission in the spectrum. The typical effects of degradation processes, such as chain scission and cross-linking, explain the physical properties of irradiated polymer. By increasing laser pulses probably lens surface can be reinforced by cross-linking. These indicate that the chemical bonds of $\mathrm{C}-\mathrm{O}$ and $\mathrm{C}=\mathrm{O}$ are getting weaker. The weakness is due to the UV light absorption during irradiation by laser. However, no chemical bond was broken in this experiment since no new peaks appear or vanish from the FTIR spectrum. This is due to the weak energy delivered by the ArF excimer laser. Improve the surface hydrophilicity after irradiation by multiple pulses, indicating that the surface roughness and microstructure formed on the surface resulting from irradiation have a significant role in increasing the surface hydrophilicity.

\section{Conclusion}

With systematic study and careful control of laser parameter radiation in combination with RGP lens properties, UV laser irradiation at $193 \mathrm{~nm}$ will become a useful micromachining tool for lens surface modification without changing the chemical bonds. AFM and SEM micrographs reveal the formation of the microstructure after excimer laser irradiation. Contact angle measurements have been done to investigate the wettebility changes on lenses based on laser irradiation. It indicates a hydrophilicity improvement at higher UV doses. Moreover, according to ATR-FTIR analysis, no significant change of irradiated RGP lenses is observed on chemical bands in dueto $75 \mathrm{~mJ} / \mathrm{cm}^{2}$ UV fluence. Results showed that the morphological surface changes with laser exposure, and the water contact angle decreases as the surface of the fluorosilicone acrylate material is modified. 


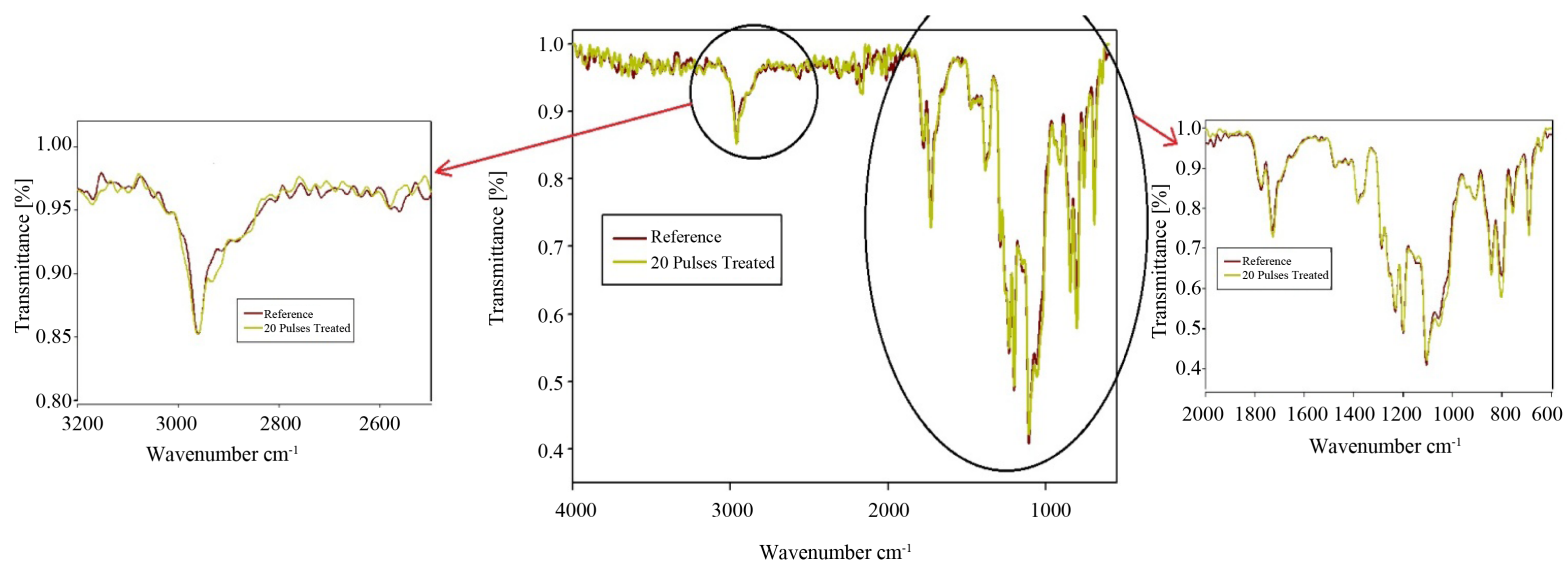

Figure 6. ATR/FTIR spectrum of untreated (Reference) and laser treated RGP lenses.

\section{Acknowledgements}

This work is supported by the Iranian Polymer and Petrochemical Institute and the Central Lab of Amirkabir University of Technology, Iran. The authors would like to thank Ms. S. Boush from Tehran University of Medical Sciences for providing us RGP contact lenses.

\section{References}

[1] Hyung, S.S., et al. (2009) Surface Modification of Rigid Gas Permeable Contact Lens Treated by Using a Low-Temperature Plasma in Air. Journal of the Korean Physical Society, 55, 2436-2440. http://dx.doi.org/10.3938/jkps.55.2436

[2] Wang, Y., et al. (2013) Plasma Surface Modification of Rigid Contact Lenses Decreases Bacterial Adhesion. Eye \& Contact Lens: Science \& Clinical Practice, 39, 376-380. http://dx.doi.org/10.1097/ICL.0b013e31829e8f73

[3] Bhatia, S., Goldberg, E.P. and Enns, J.B. (1997) Examination of Contact Lens Surfaces by Atomic Force Microscope. CLAO Journal, 23, 264-269.

[4] Giraldez, M.J., Serra, C., Lira, M., et al. (2010) Soft Contact Lens Surface Profile by Atomic Force Microscopy. Optometry and Vision Science, 87, 475-481. http://dx.doi.org/10.1097/OPX.0b013e3181e170c5

[5] Guryča, V., Hobzová, R., et al. (2007) Surface Morphology of Contact Lenses Probed with Microscopy Techniques. Contact Lens \& Anterior Eye, 30, 215-222. http://dx.doi.org/10.1016/j.clae.2007.02.010

[6] Srinivasan, R. and Braren, B. (1989) Ultraviolet Laser Ablation of Organic Polymers. Chemical Review, 89, $1303-1308$. http://dx.doi.org/10.1021/cr00096a003

[7] Rabek, J.F. (1996) Photodegradation of Polymer. Springer-Verlag, Heidelberg. http://dx.doi.org/10.1007/978-3-642-80090-0

[8] Rubahan, H.G. (1999) Laser Applications in Surface Science and Technology. Wiley, New York.

[9] Zhang, Z., Hu, X. and Luo, Z. (1996) Wavelength Sensitivity of Photo-Oxidation of Polypropylene. Polymer Degradation and Stability, 51, 93-97. http://dx.doi.org/10.1016/0141-3910(95)00210-3

[10] Torikai, A. and Hasegawa, H. (1998) Wavelength Effect on the Accelerated Photodegradation of Polymethylmethacrylate. Polymer Degradation and Stability, 61, 361-364. http://dx.doi.org/10.1016/S0141-3910(97)00119-5

[11] Gesenhues, U. (2000) Influence of Titanium Dioxide Pigments on the Photodegradation of Poly(vinyl chloride). Polymer Degradation and Stability, 68, 185-196. http://dx.doi.org/10.1016/S0141-3910(99)00184-6

[12] Geretovsky, Z., Hopp, B., Bertoti, I. and Boyd, I.W. (2002) Photodegradation of Polycarbonate under Narrow Band Irradiation at $172 \mathrm{~nm}$. Applied Surface Science, 186, 85-90. http://dx.doi.org/10.1016/S0169-4332(01)00615-8

[13] Lippert, T. and Dickinson, J.T. (2003) Chemical and Spectroscopic Aspects of Polymer Ablation: Special Features and Novel Directions. Chemical Review, 103, 453-486. http://dx.doi.org/10.1021/cr010460q

[14] Panchenko, A.N., Shulepov, M.A., Tel’minov, A.E., Zakharov, L.A., Paletsky, A.A. and Bulgakova, N.M. (2011) Pulsed IR Laser Ablation of Organic Polymers in Air: Shielding Effects and Plasma Pipe Formation. Journal of Physics D: Applied Physics, 44, Article ID: 385201. http://dx.doi.org/10.1088/0022-3727/44/38/385201

[15] Wee, S.W. and Park, S.M. (2001) Laser Ablation of Poly(methyl methacrylate) at $266 \mathrm{~nm}$. Bulletin of the Korean Chemical Society, 22, 914-916. 
[16] Dorronsoro, C., Siegel, J., Remon, L. and Marcos, S. (2008) Suitability of Filofocon A and PMMA for Experimental Models in Excimer Laser Ablation Refractive Surgery. Optics Express, 16, 20955-20967. http://dx.doi.org/10.1364/OE.16.020955

[17] Berns, M.W., Chao, L., Giebel, A.W., Liaw, L.H., Andrews, J. and VerSteeg, B. (1999) Human Corneal Ablation Threshold Using the 193-nm ArF Excimer Laser. Investigative Ophthalmology \& Visual Science, 40, 826-830.

[18] Spyratou, E., Asproudis, I., Tsoutsi, D., Bacharis, C., Moutsouris, K., Makropoulou, M. and Serafetinides, A.A. (2010) UV Laser Ablation of Intraocular Lenses: SEM and AFM Microscopy Examination of the Biomaterial Surface. Applied Surface Science, 256, 2539-2545. http://dx.doi.org/10.1016/j.apsusc.2009.10.101

[19] Nakagawa, T., Maeda, N., Cekic, O., Fujikado, T., Tano, Y., Murakami, A., et al. (2008) Corneal Ablation with New 193 nm Solid-State Laser: Preliminary Experiments. Journal of Cataract Refractive Surgery, 34, 1019-1023. http://dx.doi.org/10.1016/j.jcrs.2008.02.034

[20] Wisniewski, M., Sionkowska, A., Kaczmarek, H., Skopinska, J., Lazare, S. and Tokarev, V. (2006) The Influence of KrF Excimer Laser Irradiation on the Surface of Collagen and Collagen/PVP Films. International Journal of Photoenergy, 2006, Article ID: 35126.

[21] Jaleh, B., Parvin, P., Sheikh, N., Zamanipour, Z. and Sajad, B. (2007) Hydrophilicity and Morphological Investigation of Polycarbonate Irradiated by ArF Excimer Laser. Nuclear Instruments and Methods in Physics Research Section B, 265, 330-333. http://dx.doi.org/10.1016/j.nimb.2007.08.067

[22] Kowal, A. (2005) Application of STM and AFM Techniques for the Investigation of Corrosion Processes and Materials Protection. Materials Protection, 46, 44-46.

[23] Saffar, A.P., Jaleh, B., Parvin, P., Wanichapichart, P. and Farshchi-Tabrizi, M. (2014) Surface Modification and Dielectric Response Investigation of Cellulose Acetate Membrane Treated by ArF Excimer Laser. Open Access Library Journal, 1, e488.

[24] Tsilimbaris, M.K., Lesniewska, E., Lydataki, S., Le Grimellec, C., Goudonnet, J.P. and Pallikaris, I.G. (2000) The Use of Atomic Force Microscopy for the Observation of Corneal Epithelium Surface. Investigative Ophthalmology \& Visual Science, 41, 680-686. 